Article

\title{
Truth and Myths about 2D Tensegrity Trusses
}

\author{
Paulina Obara ${ }^{1, * \mathbb{D}}$, Joanna Kłosowska ${ }^{1}$ and Wojciech Gilewski ${ }^{2}$ \\ 1 Kielce University of Technology, Faculty of Civil Engineering and Architecture, 25-314 Kielce, Poland; \\ j.klosowska@tu.kielce.pl \\ 2 Warsaw University of Technology, Faculty of Civil Engineering, 00-637 Warsaw, Poland; \\ w.gilewski@il.pw.edu.pl \\ * Correspondence: paula@tu.kielce.pl; Tel.: +48-34-24-693
}

Received: 16 November 2018; Accepted: 31 December 2018; Published: 6 January 2019

check for updates

Featured Application: We present an evaluation of 2D structural models of specific truss structures named tensegrities. Proper understanding of this unusual structure (according to the proposed definition and methods of analysis) is necessary for specific applications in building and bridge construction, deployable structures, and smart structures with monitoring, self-control, self-repair, and active control. New and future potential applications of the concept are tensegrity inspired metamaterials with unique mechanical properties.

\begin{abstract}
The concept of tensegrity is understood in many ways. This term is often improperly used for structures that have some, but not necessarily the key, tensegrity properties. The concept of tensegrity systems is misused in reference to both mathematical models and completed engineering structures. The aim of the study is to indicate which of the plane (2D) trusses presented in the literature are erroneously classified as tensegrities. Singular value decomposition of the compatibility matrix and spectral analysis of the stiffness matrix with the effect of self-equilibrated forces is used for the analysis. A new precise definition of tensegrity trusses is proposed and implemented.
\end{abstract}

Keywords: tensegrity; singular value decomposition (SVD); spectral analysis

\section{Introduction}

Tensegrity structures consist of compression (struts) and tensile (cables) components which stabilize each other through pre-stress. The idea of tensegrity was first described about 60 years ago, but no precise, nor general, definition has currently been agreed upon. This thereby paves the way for confusion and misuse of the term in technical applications. The term is often used for trusses that have little to do with the tensegrity principle as defined by the creators of this idea.

The first patented definitions of tensegrity are very general. Fuller [1] described tensegrity systems as "islands of compression in a sea of tension". Snelson patented the system [2] which he called "Continuous Tension, Discontinuous Compression Structures." Emmerich [3] added the condition of self-stress state: Tensegrity structures consist of rods mounted in such a way that the struts remain physically isolated in a continuous set of cables. All these elements must be very close to one another and interconnected by tensional pre-stress. No external supports or anchors are required. It makes a structure as strong as the self-supporting structure, hence the name self-stress state. The most widely accepted definition of tensegrity is formulated by Pugh [4], in which he combines the two previous statements: "A tensegrity system is established when a set of discontinuous compression components interacts with a set of continuous tensile components to define a stable volume in space." This definition was narrowed by Motro [5,6]: "A tensegrity system is a system in a stable self-equilibrated state comprising a discontinuous set of compressed components inside a continuum of tensioned components." Hanaor [7] describes tensegrity structures as "internally 
prestressed, free-standing pin-jointed networks, in which the cables or tendons are tensioned against a system of bars or struts". A broader interpretation is proposed by Miura and Pellegrino [8,9] who classify tensegrity as "any structure realized from cables and struts, to which a state of prestress is imposed that imparts tension to all cables". A narrower interpretation, also by Miura and Pellegrino, adds to the above definition the notion that "as well as imparting tension to all cables, the state of prestress serves the purpose of stabilising the structure, thus providing first-order stiffness to its infinitesimal mechanisms". Wang [10] defines tensegrity structures as "Self-stressed equilibrium cable networks in which a continuous system of cables (tendons) are stressed against a discontinuous system of struts; or structures composed of tensegrity simplexes". Zhang and Ohsaki [11], based on existing definitions, describe characteristics of a tensegrity structure as follows: "(1) The structure is free-standing, without any support. (2) The structural members are straight. (3) There are only two different types of structural members: struts carrying compression and cables carrying tension. (4) The struts do not contact with each other at their ends." Skelton et al. [12-18] take a different approach. They introduce the concept of tensegrity configuration: "Configuration forms a tensegrity configuration if the given configuration can be stabilized by some set of internal tensile members, i.e., connected between the right bodies" [12] and classes of structural systems: "A tensegrity configuration that has no contacts between its right bodies is a class 1 tensegrity system, and a tensegrity system with as many as k right bodies contact is a class k tensegrity system." [13].

The definition proposed in this paper is based on the characteristics of tensegrities, closely related to their benefits. These include stabilization through tension, efficiency, deployability and easy tunability, the ability to be reliably modeled, and more precise controllability [13,14]. The properties demonstrated by tensegrity structures have received increased attention, especially from civil engineers in applications such as bridges, domes and towers [19-22], or in deployable structures and smart structures with monitoring, self-control, self-repair, and active control $[9,23,24]$. The potential of the tensegrity concept has inspired new metamaterials. Metamaterials are artificially invented materials that have properties which are not observed in nature. These are composite structures with extreme unusual mechanical properties. In recent years increased interest in the research of metamaterials has been observed. The different types of metamaterials, their unique properties and advantages are presented in [25]. Some researchers are considering the development of new complex tensegrity cells and the application of the tensegrity concept to metamaterials [26-30].

The arbitrary use or misuse of the word tensegrity is particularly noticeable in descriptions of cable-strut structures, for example in bridge engineering [20]. A precise understanding of this unusual structure is essential.

In the absence of externally applied loads, tensegrity, as a type of form-active structure, needs self-equilibrium configuration as determined in the process called form-finding. Over the past decades, many research efforts have been devoted to searching for effective form-finding methods $[4,6,11,12,31-41]$. A thorough review of the existing methods for tensegrity structures is included in [42-45] and new form-finding approaches continue to be invented [46-48].

Previously used methods, usually complex and time-consuming, are well-suited for searching for equilibrium configurations but often fail to address all characteristic features of tensegrity structures. In this paper, a qualitative analysis of truss matrices (compatibility matrix and stiffness matrix with the effect of self-equilibrated forces) is used to search for a tensegrity form. The matrices are established using the finite element method. This simple approach allows researchers to define the characteristic features of tensegrity structures.

Both plane and three-dimensional trusses can be analyzed with this method. Engineering design principles allow the use of two-dimensional computational models, which, compared to the spatial structures, far more intuitively understandable and have limited diversity. The aim of this paper is to analyze plane (2D) tensegrity structures found in the literature. The authors' own precise definition proposed and implemented here, is a result of detailed analysis of the descriptions of tensegrity characteristics. 
The concept of tensegrity systems is misused in reference to both mathematical models and completed engineering structures where the terms "tensegrity bridges" or "tensegrity domes" are applied to the cable-strut models. The proposed evaluation method will allow proper understanding of these unique structures and ensure the correct use of the term in all applications.

\section{Definition of Tensegrity}

With regard to structural mechanics, the presence of self-stress states (understood as the system of self-equilibrated normal forces which satisfies homogeneous equations of equilibrium) and infinitesimal mechanisms which are stabilized by these states are the most important features of tensegrity structures. In this paper, considerations are limited to "pin-jointed plane structures" and the definition of tensegrity formulated by Kasprzak [20] is used. Based on the definitions known from the literature, tensegrity structures demonstrate the following characteristic features:

- $T$-the structure is a truss,

- $S$-there is a self-stress state,

- $M$-there is an infinitesimal mechanism stiffened by the self-stress state,

- $\quad D$-the extremities of compressed components (struts) do not touch each other and struts constitute a discontinuous set,

- I-the set of compressed components is included inside the set of tensile components,

- $\quad C$-tensile elements have no rigidity in compression — these are cables.

The characteristics above are used to classify structures as "pure tensegrities" or "structures with tensegrity features".

"Pure tensegrity" is represented by a structure that closely meets all the requirements arising from the definition of tensegrity and defining its specific properties. A tensegrity structure is a truss in which there is an infinitesimal mechanism stiffened by a self-stress state. Components in compression create a discontinuous system inside a continuous system of components in tension, which have no compressive rigidity. The structures that have all of the six features $(T+S+M+D+I+C)$ are classified in the "pure tensegrity" group.

"Structures with tensegrity features" include a wider range of systems in which some properties of tensegrity can be ignored, e.g. a truss in a self-stress state, with tensile elements having no compressive rigidity, demonstrating at least one of the following features: The presence of an infinitesimal mechanism stabilized by self-stress state, the discontinuity of the system of compressed components, and/or the use of compressed elements inside a set of tension components. Structures assigned to this group fulfil three obligatory criteria $(T+S+C)$ and have at least one of the features: $M, D$, or $I$.

From an engineering perspective, it is very important that the structures have all six features. Only pure tensegrities possess all the benefits of tensegrity structures, including the ability to control their stiffness and natural frequency by modifying the self-stress level.

Singular value decomposition of the compatibility matrix is used to determine the states of self-stress $(S)$ and mechanisms $(M)$. The nonlinear analysis with the use of geometric stiffness matrix, which takes into account the impact of the self-stress state, allows establishing whether the mechanism is infinitesimal or finite. The other characteristic features of tensegrity structures like $D, I$, and $C$ are determined indirectly by the identified self-stress state.

\section{Mathematical Description}

The plane truss finite element of Young modulus $E_{e}$, cross-sectional area $A_{e}$ and lengths $L_{e}$ (Figure 1a) is used to model the components of tensegrity structures. In global coordinate system $(x, y)$ a truss element is described respectively by the compatibility matrix $\mathbf{B}_{e}\left(\in \mathbb{R}^{1 \times 4}\right)$ and by the geometric stiffness matrix $\mathbf{K}_{G e}\left(\in \mathbb{R}^{4 \times 4}\right)$, taking into account the impact of the self-stress state $S_{e}$ : 


$$
\mathbf{B}_{e}=\left[\begin{array}{llll}
-c & -s & c & s
\end{array}\right], \mathbf{K}_{G e}=\frac{S_{e}}{L_{e}}\left[\begin{array}{cc}
\mathbf{I}_{e} & -\mathbf{I}_{e} \\
-\mathbf{I}_{e} & \mathbf{I}_{e}
\end{array}\right] ; \mathbf{I}_{e}=\left[\begin{array}{cc}
s^{2} & -c s \\
-c s & c^{2}
\end{array}\right],
$$

where: $c=\frac{x_{j}-x_{i}}{L_{e}}, s=\frac{y_{j}-y_{i}}{L_{e}}$.

The qualitative analysis focuses on $n$-membered $(e=1,2, \ldots, n)$ two-dimensional trusses, described by elasticity matrix $\mathbf{E}\left(\in \mathbb{R}^{n \times n}\right)$ :

$$
\mathbf{E}=\operatorname{diag}\left[\begin{array}{llll}
\frac{E_{1} A_{1}}{L_{1}} & \frac{E_{2} A_{2}}{L_{2}} & \ldots & \frac{E_{n} A_{n}}{L_{n}}
\end{array}\right]
$$

with $m$ degrees of freedom $\mathbf{q}\left(\in \mathbb{R}^{m \times 1}\right)$ :

$$
\mathbf{q}=\left[\begin{array}{llll}
q_{1} & q_{2} & \ldots & q_{m}
\end{array}\right]^{T}
$$

The compatibility matrix $\mathbf{B}\left(\in \mathbb{R}^{n \times m}\right)$ and the geometric stiffness matrix $\mathbf{K}_{G}\left(\in \mathbb{R}^{m \times m}\right)$ for trusses are determined using the finite element formalism [49-51]:

$$
\mathbf{B}=\left[\begin{array}{c}
\mathbf{B}_{1} \mathbf{C}_{1} \\
\mathbf{B}_{2} \mathbf{C}_{2} \\
\ldots \\
\mathbf{B}_{n} \mathbf{C}_{n}
\end{array}\right], \mathbf{K}_{G}=\sum_{i=1}^{n} \mathbf{C}_{e}^{T} \mathbf{K}_{G e} \mathbf{C}_{e},
$$

where $\mathbf{C}_{e}\left(\in \mathbb{R}^{4 \times m}\right)$ is a Boolean matrix. It is assumed that the number of global degrees of freedom of each element $q_{i}(i=1,2,3,4)$ corresponds to the number of global nodes of elements $n_{1}, n_{2}$ as shown in Figure $1 \mathrm{~b}$. Consequently, the non-zero elements of $\mathbf{C}_{e}$ for each element can be expressed as $C_{i q_{i}}=1$.

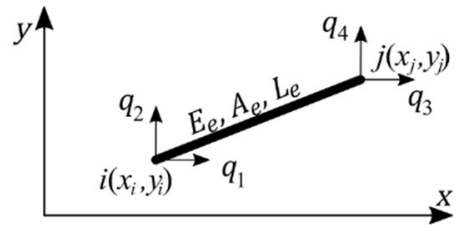

(a)

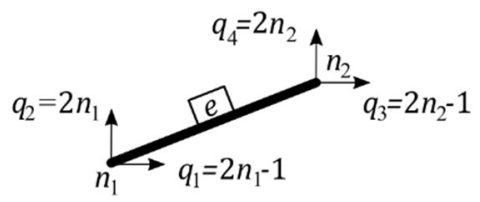

(b)

Figure 1. (a) Plane truss finite element, (b) global degrees of freedom of element $e$.

Equilibrium equations for trusses can be written in a stress form:

$$
\mathbf{B}^{T} \mathbf{S}=\mathbf{P},
$$

where $\mathbf{S}\left(\in \mathbb{R}^{n \times 1}\right)$ is the normal force vector and $\mathbf{P}\left(\in \mathbb{R}^{m \times 1}\right)$ is the load vector, or via nodal displacements:

$$
\mathbf{K}_{L} \mathbf{q}=\mathbf{P},
$$

where $\mathbf{K}_{L}\left(\in \mathbb{R}^{m \times m}\right)$ is the linear stiffness matrix:

$$
\mathbf{K}_{L}=\mathbf{B}^{T} \mathbf{E B} .
$$

To take into account the non-linearity of the equilibrium equations and the influence of the prestress (self-stress) in the structure, the geometric stiffness matrix $(4)_{2}$ is introduced. Then the system of displacement equations (6) takes the form:

$$
\left(\mathbf{K}_{L}+\mathbf{K}_{G}\right) \mathbf{q}=\mathbf{P} .
$$

A mathematical description of tensegrity-like pin-jointed structures can be found in [51-56]. 
The qualitative analysis of the set of equations for the structure can be done through singular value decomposition [57-63] of the compatibility matrix B [64-66]. The singular value decomposition of matrix $\mathbf{B}$ is a factorization in the form:

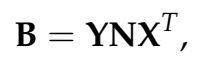

where $\mathbf{Y}\left(\in \mathbb{R}^{n \times n}\right)$ and $\mathbf{X}\left(\in \mathbb{R}^{m \times m}\right)$ are the orthogonal matrices and $\mathbf{N}\left(\in \mathbb{R}^{n \times m}\right)$ is rectangular diagonal matrix. The orthogonal matrices $\mathbf{Y}$ and $\mathbf{X}$ as well as matrix $\mathbf{N}$ are related to eigenvectors and eigenvalues of the following problems:

$$
\begin{aligned}
& \left(\mathbf{B B}^{T}-\mu \mathbf{I}\right) \mathbf{y}=\mathbf{0}, \\
& \left(\mathbf{B}^{T} \mathbf{B}-\lambda \mathbf{I}\right) \mathbf{x}=\mathbf{0} .
\end{aligned}
$$

The solutions to the (10) and (11) eigen-problems, can be expressed as:

$$
\begin{aligned}
& \mathbf{M}=\operatorname{diag}\left[\begin{array}{llll}
\mu_{1} & \mu_{2} & \ldots & \mu_{n}
\end{array}\right], \mathbf{Y}=\left[\begin{array}{llll}
\mathbf{y}_{1} & \mathbf{y}_{2} & \ldots & \mathbf{y}_{n}
\end{array}\right] \\
& \mathbf{L}=\operatorname{diag}\left[\begin{array}{llll}
\lambda_{1} & \lambda_{2} & \ldots & \lambda_{m}
\end{array}\right], \mathbf{X}=\left[\begin{array}{llll}
\mathbf{x}_{1} & \mathbf{x}_{2} & \ldots & \mathbf{x}_{m}
\end{array}\right] .
\end{aligned}
$$

The eigenvalues matrices $\mathbf{M}\left(\in \mathbb{R}^{n \times n}\right)$ and $\mathbf{L}\left(\in \mathbb{R}^{m \times m}\right)$ are dependent on the matrix $\mathbf{N}$ of the decomposition (9):

$$
\mathbf{M}=\mathbf{N N}^{T}, \mathbf{L}=\mathbf{N}^{T} \mathbf{N}
$$

One can notice that the product $\mathbf{B B}^{T}$ can be considered as a matrix of symmetrized equations of equilibrium (5) with non-negative eigenvalues. Zero eigenvalues (if any) are related to the non-zero solution of homogeneous equations called a self-stress, or more precisely, self-equilibrated normal forces that satisfies homogeneous equations of equilibrium. The self-stress can be considered an eigenvector related to zero eigenvalue. In a similar way, the product $\mathbf{B}^{T} \mathbf{B}$ can be considered as a particular form of a linear stiffness matrix (7) with unit elasticity matrix $\mathbf{E} \equiv \mathbf{I}$. The eigenvalues are non-negative. Zero eigenvalues (if any) are related to the finite or infinitesimal mechanisms, which can be considered an eigenvector related to zero eigenvalue. Finite mechanisms (rigid-body motions) refer to the motions that do not change the distance between any pair of nodes. Infinitesimal mechanisms describe the local geometrical variability in the range of small displacements. Generally, the information from the null-space analysis alone is insufficient to determine the difference.

To establish whether the mechanism is infinitesimal or finite, it is necessary to apply nonlinear analysis with the use of geometric stiffness matrix (8), which is possible if the self-stress exists. If the eigenvalues of $\left(\mathbf{K}_{L}+\mathbf{K}_{G}\right)$ are positive numbers, the mechanism is infinitesimal. It means the structure is stable. Zero eigenvalues are related to finite mechanisms. A negative eigenvalue represents instability of the structure.

Full solutions to the eigen-problem of the stiffness matrix, taking into account the geometric stiffness matrix:

$$
\left(\mathbf{K}_{L}+\mathbf{K}_{G}-\sigma \mathbf{I}\right) \mathbf{z}=0
$$

can be expressed in the condensed form:

$$
\mathbf{K}_{L}+\mathbf{K}_{G}=\mathbf{Z O Z}^{T}
$$

where:

$$
\mathbf{O}=\operatorname{diag}\left[\begin{array}{llll}
\sigma_{1} & \sigma_{2} & \ldots & \sigma_{n}
\end{array}\right], \mathbf{Z}=\left[\begin{array}{llll}
\mathbf{z}_{1} & \mathbf{z}_{2} & \ldots & \mathbf{z}_{n}
\end{array}\right]
$$

are the matrices of eigenvalues and of normalized eigenvectors, respectively. 


\section{Results}

The aim of the study is to indicate which of the plane (2D) trusses presented in the literature are wrongly classified as tensegrities. To do this, the qualitative analysis of selected trusses was carried out. Singular value decomposition of compatibility matrix $\mathbf{B}$ and spectral analysis of stiffness matrix with the effect of self-equilibrated forces $\left(\mathbf{K}_{L}+\mathbf{K}_{G}\right)$ were used for the analysis. Since the characteristic features of tensegrity structures do not depend on geometrical and material characteristics, it was assumed that the constant longitudinal stiffness $E_{e} A_{e}=1$ and constant lengths $a=1$. Eighteen plane tensegrity structures were analyzed. The results were presented in two ways (mathematical and graphical)—for selected structures the following matrices were determined:

- $\quad \mathbf{L}$-eigenvalues of matrix $\mathbf{B}^{\mathrm{T}} \mathbf{B}$,

- $\quad \mathbf{x}_{i}$ - eigenvectors (if any) of $\mathbf{B}^{\mathrm{T}} \mathbf{B}$ corresponding to the zero eigenvalues $\lambda_{i}$ in $\mathbf{L}$ responsible for the existence of the mechanism $(M)$,

- $\mathbf{M}$-eigenvalues of matrix $\mathbf{B B}^{\mathrm{T}}$,

- $\quad \mathbf{y}_{i}$ - eigenvectors of $\mathbf{B B}^{\mathrm{T}}$ corresponding to the zero eigenvalues $\mu_{i}$ (if any) in $\mathbf{M}$ responsible for the existence of the self-stress state $(S)$,

- $\mathbf{O}$-eigenvalues of matrix $\left(\mathbf{K}_{L}+\mathbf{K}_{G}\right)$ with the self-stress taken from the singular value decomposition (SVD).

In other cases, only the values of self-stress state $S_{e}$ (values of self-stress were normalized such that $\sum_{i}^{n} S_{i}^{2}=1$; where $n$-number of elements) and forms of mechanisms (if any) were shown. The calculations were carried out in the Mathematica environment.

For the purpose of this paper, the plane (2D) trusses defined in the literature as "tensegrities" were classified into three groups: "Structures with tensegrity features", "pure tensegrities" and "non tensegrities".

Figure 2a shows the first structure under analysis. It is the most popular structure in the literature $[8,12,15-18,37,41,42,64,67-78]$, usually referred to as "the simplest $2 \mathrm{D}$ tensegrity structure" [77]. It is a truss $(T)$ with six elements $(n=6)$ and five degrees of freedom (d.o.f.) $(m=5)-\mathbf{q}=\left[\begin{array}{lllll}q_{3} & q_{4} & q_{5} & q_{6} & q_{7}\end{array}\right]^{T}$. For this truss the compatibility matrix $\mathbf{B}\left(\in \mathbb{R}^{6 \times 5}\right)$ is:

$$
\mathbf{B}=\left[\begin{array}{ccccc}
0 & 1 & 0 & 0 & 0 \\
-1 & 0 & 1 & 0 & 0 \\
0 & 0 & 0 & 1 & 0 \\
0 & 0 & 0 & 0 & 1 \\
-0.707 & 0.707 & 0 & 0 & 0.707 \\
0 & 0 & 0.707 & 0.707 & 0
\end{array}\right]
$$

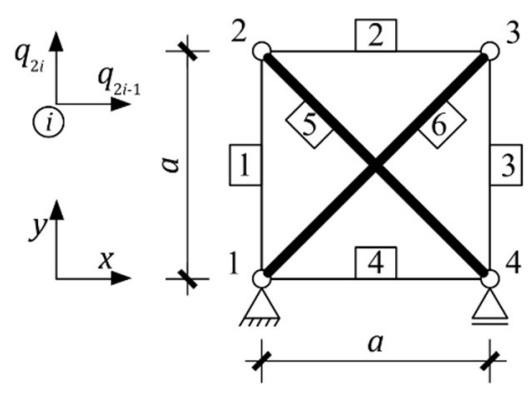

(a)

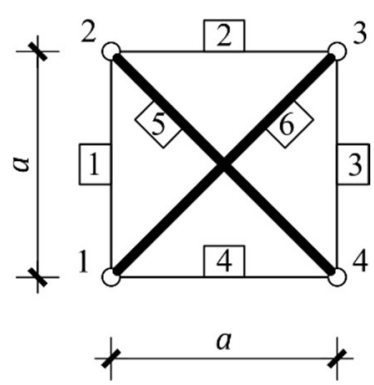

(b)

Figure 2. The " $X$ " truss: (a) supported, (b) unsupported. 
The eigenvalues of both $\mathbf{B}^{\mathrm{T}} \mathbf{B}$ and $\mathbf{B B}^{\mathrm{T}}$ matrices are respectively:

$$
\mathbf{L}=\operatorname{diag}\left[\begin{array}{lllll}
2.89 & 2 & 1.35 & 1 & 0.25
\end{array}\right] ; \mathbf{M}=\operatorname{diag}\left[\begin{array}{llllll}
2.89 & 2 & 1.35 & 1 & 0.25 & 0
\end{array}\right] .
$$

There is no zero eigenvalue in $\mathbf{L}$, which means that no mechanism is identified. The zero eigenvalue in $\mathbf{M}$ is responsible for the existence of the self-stress state $(S)$ :

$$
\mathbf{y}_{6}=\left\{\begin{array}{llllll}
0.35 & 0.35 & 0.35 & 0.35 & -0.5 & -0.5
\end{array}\right\} .
$$

In this case, all eigenvalues of the matrix $\left(\mathbf{K}_{L}+\mathbf{K}_{G}\right)$ are positive:

$$
\mathbf{O}=\operatorname{diag}\left[\begin{array}{lllll}
2.71 & 2.38 & 1.49 & 0.77 & 0.29
\end{array}\right],
$$

which means the structure is stable. For this truss the system of compression members (thick line) is discontinuous $(D)$ and included inside the set of components in tension $(I)$, which are cables (C). However, because of the absence of the mechanism, the truss shares only some features with a tensegrity.

If unsupported " $\mathrm{X}$ " truss is analyzed (Figure $2 \mathrm{~b})$, there are eight d.o.f. $(m=8)$ and the compatibility matrix $\mathbf{B}\left(\in \mathbb{R}^{6 \times 8}\right)$ is as follows:

$$
\mathbf{B}=\left[\begin{array}{cccccccc}
0 & -1 & 0 & 1 & 0 & 0 & 0 & 0 \\
0 & 0 & -1 & 0 & 1 & 0 & 0 & 0 \\
0 & 0 & 0 & 0 & 0 & 1 & 0 & -1 \\
-1 & 0 & 0 & 0 & 0 & 0 & 1 & 0 \\
0 & 0 & -0.707 & 0.707 & 0 & 0 & 0.707 & -0.707 \\
-0.707 & -0.707 & 0 & 0 & 0.707 & 0.707 & 0 & 0
\end{array}\right]
$$

Matrices $\mathbf{L}\left(\in \mathbb{R}^{8 \times 8}\right)$ and $\mathbf{M}\left(\in \mathbb{R}^{6 \times 6}\right)$ are respectively:

$$
\mathbf{L}=\operatorname{diag}\left[\begin{array}{llllllll}
4 & 2 & 2 & 2 & 2 & 0 & 0 & 0
\end{array}\right] ; \mathbf{M}=\operatorname{diag}\left[\begin{array}{llllll}
4 & 2 & 2 & 2 & 2 & 0
\end{array}\right] .
$$

There are three zero eigenvalues in $\mathbf{L}$, which means three mechanisms $(M)$ are identified (Figure 3):

$$
\begin{gathered}
\mathbf{x}_{7}=\left\{\begin{array}{llllllll}
0.51 & 0.11 & 0.43 & 0.11 & 0.43 & 0.19 & 0.51 & 0.19
\end{array}\right\}, \\
\mathbf{x}_{8}=\left\{\begin{array}{lllllllll}
-0.33 & 0.57 & 0.25 & 0.57 & 0.25 & -0.01 & -0.33 & -0.01
\end{array}\right\}, \\
\mathbf{x}_{9}=\left\{\begin{array}{llllllll}
0.04 & 0.18 & -0.35 & 0.18 & -0.35 & 0.58 & 0.04 & 0.58
\end{array}\right\} .
\end{gathered}
$$

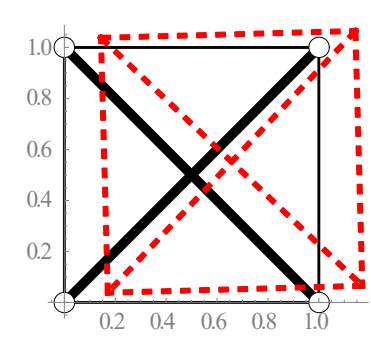

(a)

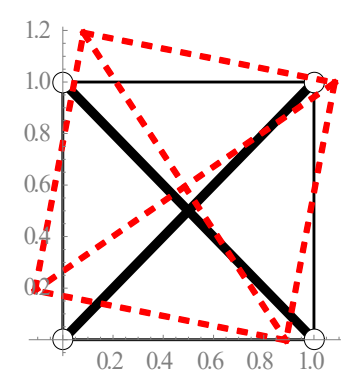

(b)

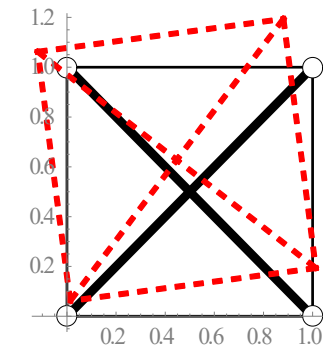

(c)

Figure 3. Mechanisms of unsupported " $X$ " truss: (a) $\mathbf{x}_{7},(\mathbf{b}) \mathbf{x}_{8},(\mathbf{c}) \mathbf{x}_{9}$. 
The zero eigenvalue in $\mathbf{M}$ is responsible for the existence of the self-stress state ( $S$ ) defined by the same eigenvector as for the supported truss:

$$
\mathbf{y}_{6}=\left\{\begin{array}{llllll}
0.35 & 0.35 & 0.35 & 0.35 & -0.5 & -0.5
\end{array}\right\} .
$$

In this case, three eigenvalues of the matrix $\left(\mathbf{K}_{L}+\mathbf{K}_{G}\right)$ are zero:

$$
\mathbf{O}=\operatorname{diag}\left[\begin{array}{llllllll}
3.41 & 2.71 & 2.71 & 2.12 & 1.29 & 0 & 0 & 0
\end{array}\right],
$$

It means the mechanisms are finite-a distance between any pair of nodes do no change.

There are four structures with similar features wrongly termed "tensegrity" in the literature:

- $\quad$ the truss $(T)$ with five elements $(n=5)$ and four d.o.f. $(m=4)[79,80]$ (Figure $4 a)$,

- the truss $(T)$ with 14 components $(n=14)$ and 13 d.o.f. $(m=13)$ [16,81-85] (Figure $4 b)$,

- the modified truss $(T)[20]$ from example presented later $[6,20]$ with ten components $(n=10)$ and nine d.o.f. $(m=9)$ (Figure 4c),

- $\quad$ the truss $(T)$ with ten elements $(n=10)$ and seven d.o.f. $(m=7)$ [86] (Figure $4 d)$.

In the first three cases (Figure $4 a-c$ ) there is one zero eigenvalue in matrix $\mathbf{M}$, which is responsible for the existence of one self-stress state $(S)$ shown in Figure $4 \mathrm{a}-\mathrm{c}$. The system of compression members (thick red line) is discontinuous $(D)$ and included inside the set of components in tension $(I)$, which are cables $(C)$.

The truss shown in Figure $4 \mathrm{~d}$ has three zero eigenvalues in matrix $\mathbf{M}$ responsible for the existence of three self-stress states $(S)$. These states need to be considered together. Superposition and normalization of self-stress states were performed, as shown in Figure 4d. For this truss the system of compression members is inside the set of tensioned elements $(I)$, which are cables $(C)$ but it does not satisfy the condition of discontinuity. According to the Skelton's definition [13], it is a class 2 tensegrity system - a system with two compressive elements connected at the nodes.

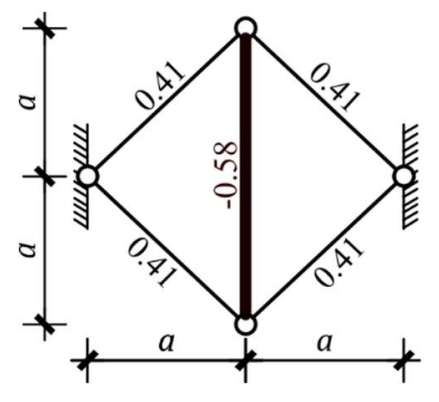

(a)

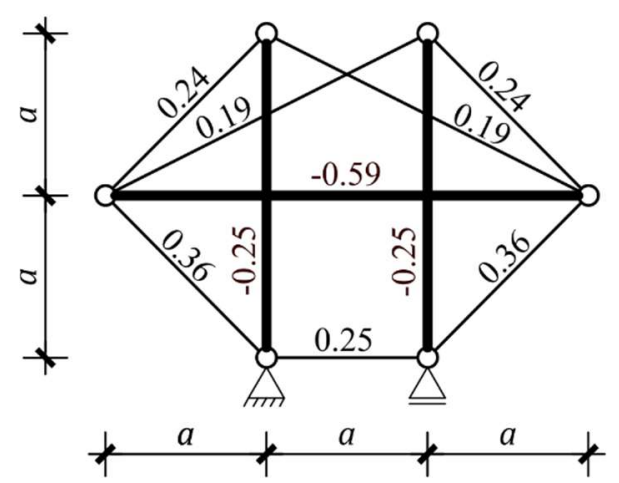

(c)

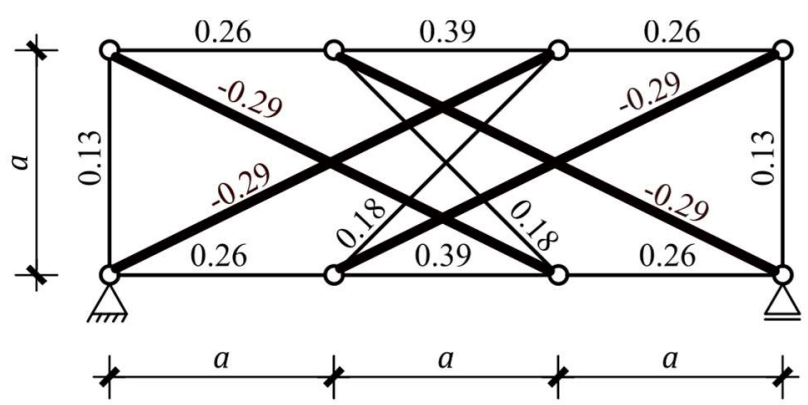

(b)

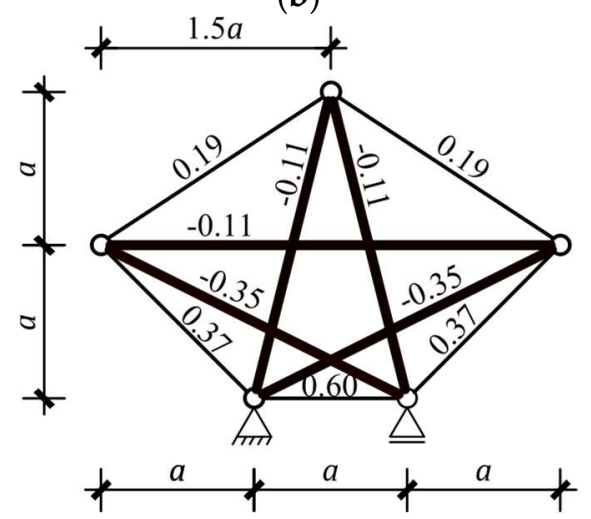

(d)

Figure 4. Self-stress values for fourtrusses (a-d) with tensegrity features. 
For these trusses there are no zero eigenvalues in matrix $\mathbf{L}$, which means that the system lacks the mechanisms. From the perspective of structural mechanics, the mechanism is one of the most important tensegrity features-the uniqueness of tensegrity structures is based on the fact that states of self-stress stabilize existing mechanisms. Because of the absence of the mechanism, these trusses are only structures with tensegrity features. The term "tensegrity" used for the above examples in the references $[6,8,12,15-18,20,37,41,42,64,67-86]$ is not sufficiently accurate.

The structure in Figure 5a represents the second group of structures. It is a truss $(T)$ with eight elements $(n=8)$ and eight d.o.f. $(m=8)[19,77,85]-\mathbf{q}=\left[\begin{array}{llllllll}q_{3} & q_{4} & q_{5} & q_{6} & q_{9} & q_{10} & q_{11} & q_{12}\end{array}\right]^{T}$. In this example, the compatibility matrix is square $\mathbf{B}\left(\in \mathbb{R}^{8 \times 8}\right)$, hence matrices $\mathbf{L}$ and $\mathbf{M}\left(\in \mathbb{R}^{8 \times 8}\right)$ are the same:

$$
\mathbf{L}=\mathbf{M}=\operatorname{diag}\left[\begin{array}{llllllll}
1.73 & 1.62 & 1.62 & 1.41 & 1.00 & 0.62 & 0.62 & 0
\end{array}\right]
$$

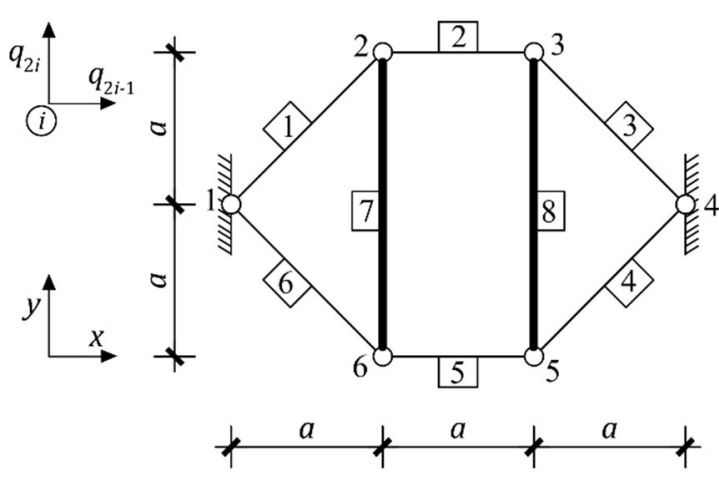

(a)

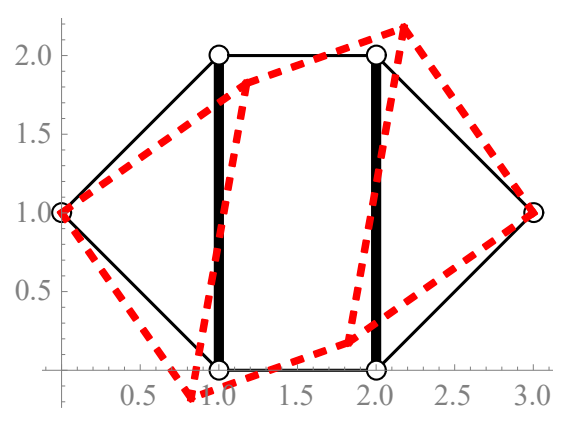

(b)

Figure 5. First pure tensegrity truss: (a) geometry, (b) infinitesimal mechanism $\mathbf{x}_{8}$.

The zero eigenvalue in $\mathbf{L}$ and $\mathbf{M}$ is responsible for the presence of the mechanism $(M)$ (Figure $5 b$ ):

$$
\mathbf{x}_{8}=\left\{\begin{array}{llllllll}
0.35 & -0.35 & 0.35 & 0.35 & -0.35 & -0.35 & -0.35 & 0.35
\end{array}\right\},
$$

and the self-stress state (S):

$$
\mathbf{y}_{8}=\left\{\begin{array}{llllllll}
0.41 & 0.29 & 0.41 & 0.41 & 0.29 & 0.41 & -0.29 & -0.29
\end{array}\right\} .
$$

In this case, all eigenvalues of the matrix $\left(\mathbf{K}_{L}+\mathbf{K}_{G}\right)$ are positive:

$$
\mathbf{O}=\operatorname{diag}\left[\begin{array}{llllllll}
2.54 & 2.23 & 2.10 & 1.45 & 1.12 & 0.47 & 0.47 & 0.16
\end{array}\right],
$$

thus the mechanism is balanced by the self-stress state-the mechanism is infinitesimal (describes the local geometrical variability). For this truss, the system of compression members (thick red line) is discontinuous $(D)$ and included inside the set of elements in tension $(I)$, which are cables $(C)$. This is a pure tensegrity with one infinitesimal mechanism stabilized by one self-stress state.

Similar but more practical example (to be used as a computational model of stadium or hall roofs) is presented in Figure 6. The structure is a truss $(T)$ with 15 elements $(n=15)$ and 16 d.o.f. $(m=16)[20,77,85,87]-\mathbf{q}=\left[\begin{array}{lllllllllllllll}q_{3} & q_{4} & q_{5} & q_{6} & q_{7} & q_{8} & q_{9} & q_{10} & q_{13} & q_{14} & q_{15} & q_{16} & q_{17} & q_{18}\end{array}\right]^{T}$. This example is developed by extending the truss showed in Figure $5 \mathrm{a}$. Here, the compatibility matrix is rectangular $\mathbf{B}\left(\in \mathbb{R}^{15 \times 16}\right)$. The matrices $\mathbf{L}\left(\in \mathbb{R}^{16 \times 16}\right)$ and $\mathbf{M}\left(\in \mathbb{R}^{15 \times 15}\right)$ are respectively:

$\mathbf{L}=\operatorname{diag}\left[\begin{array}{llllllllllllllll}3.85 & 3.59 & 3.43 & 3.02 & 2.69 & 2.12 & 2.00 & 1.49 & 1.24 & 1.07 & 0.71 & 0.49 & 0.18 & 0.12 & 0 & 0\end{array}\right]$, 


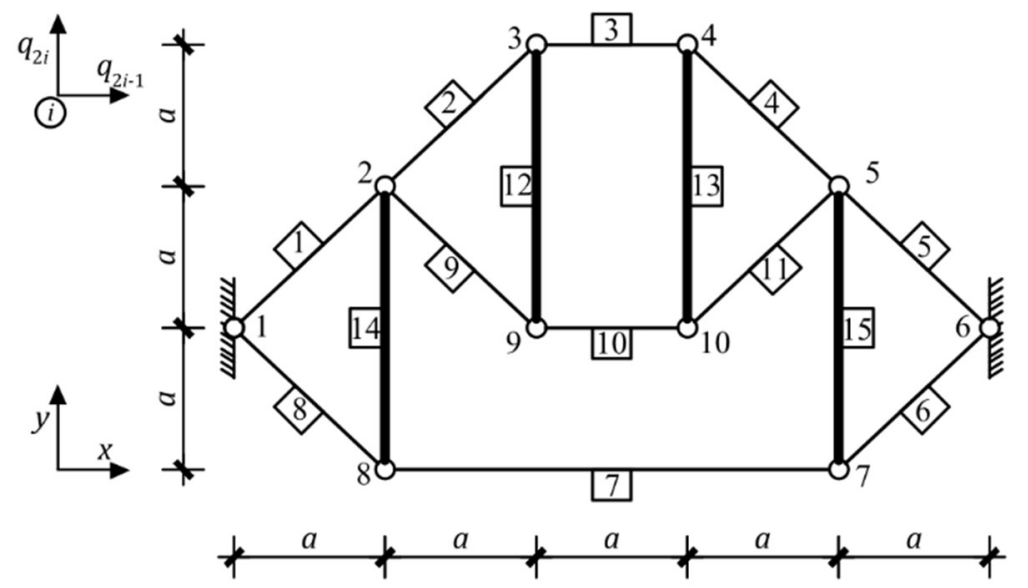

Figure 6. Second pure tensegrity truss.

Two zero eigenvalues in $\mathbf{L}$ are responsible for the existence of two mechanisms ( $M$ ) (Figure 7):

$$
\begin{aligned}
& \mathbf{x}_{15}=\left\{\begin{array}{lllllllll}
-0.24 & 0.24 & -0.27 & 0.27 & -0.27 & -0.27 & -0.24 & -0.24 & 0.24
\end{array}\right. \\
& \begin{array}{lllllll}
-0.24 & 0.24 & 0.24 & -0.21 & 0.27 & -0.21 & -0.27
\end{array}
\end{aligned}
$$

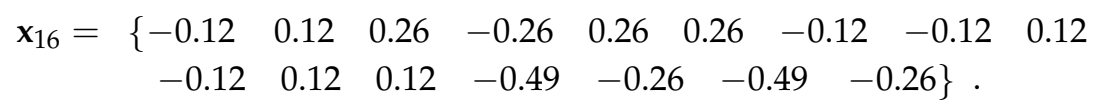

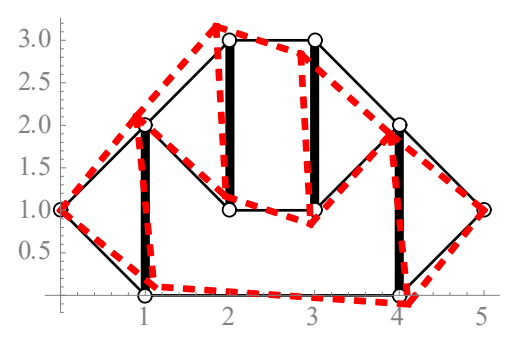

(a)

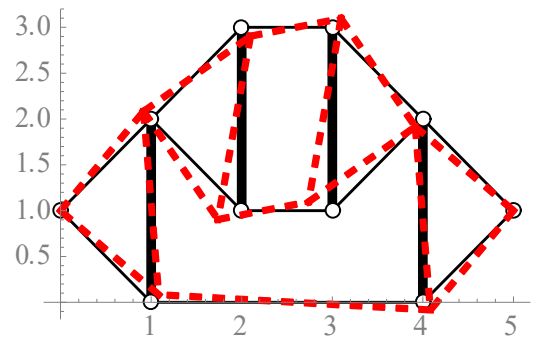

(b)

Figure 7. Infinitesimal mechanisms of the second pure tensegrity truss: (a) $\mathbf{x}_{15}$, (b) $\mathbf{x}_{16}$.

One zero eigenvalue presented in $\mathbf{M}$ is responsible for the existence of a self-stress state $(S)$ :

$$
\mathbf{y}_{16}=\left\{\begin{array}{lllllllll}
0.38 & 0.19 & 0.13 & 0.19 & 0.38 & 0.38 & 0.27 & 0.38 & 0.19 \\
& 0.13 & 0.19 & -0.13 & -0.13 & -0.27 & -0.27
\end{array}\right\} .
$$

In this case, all eigenvalues of the matrix $\left(\mathbf{K}_{L}+\mathbf{K}_{G}\right)$ are positive:

$\mathbf{O}=\operatorname{diag}\left[\begin{array}{lllllllllllllll}2.83 & 2.69 & 2.42 & 2.07 & 1.86 & 1.43 & 1.13 & 1.10 & 0.85 & 0.64 & 0.43 & 0.28 & 0.14 & 0.13 & 0.05],\end{array}\right.$

which means that mechanisms are balanced by the self-stress state-the mechanisms are infinitesimal. For this truss the system of compression members (thick line) is discontinuous $(D)$ and included inside the set of elements in tension $(I)$, which are cables $(C)$. This is a pure tensegrity with two mechanisms stabilized by one self-stress.

A selection of pure tensegrities found in the literature is shown in Figure 8:

- $\quad$ the truss $(T)$ with nine elements $(n=9)$ and nine d.o.f. $(m=9)[6,20]$ (Figure 8a), 
- $\quad$ the truss $(T)$ with nine elements $(n=9)$ and nine d.o.f. $(m=9)[4,8,9,35,38,39,41,74,85,86,88]$ (Figure 8b),

- the truss $(T)$ with 12 elements $(n=12)$ and 13 d.o.f. $(m=13)[4,38,41,70]$ (Figure $8 c$ ),

- $\quad$ the truss $(T)$ with 12 elements $(n=12)$ and 13 d.o.f. $(m=13)$ [41] (Figure $8 d$ ).

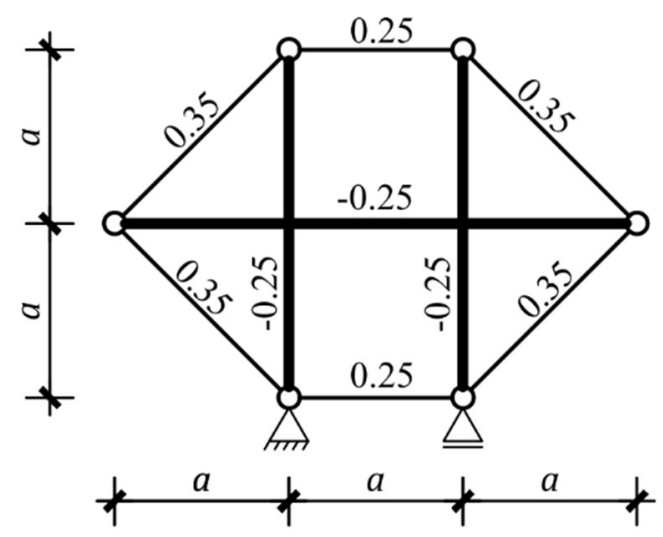

(a)

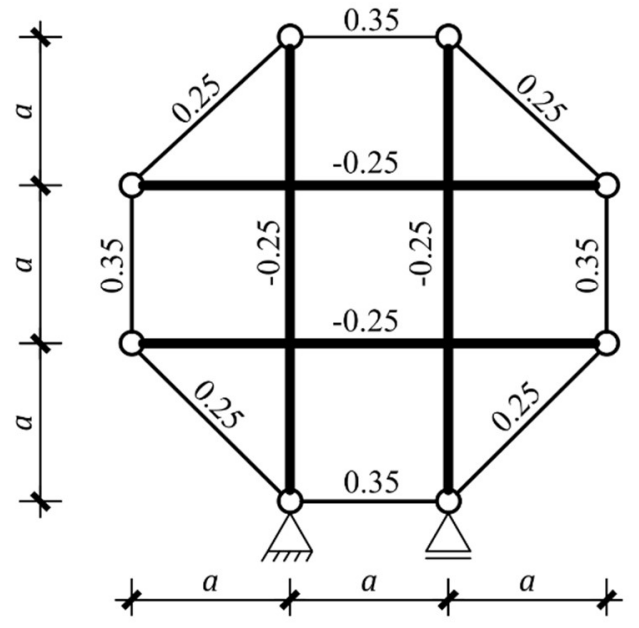

(c)

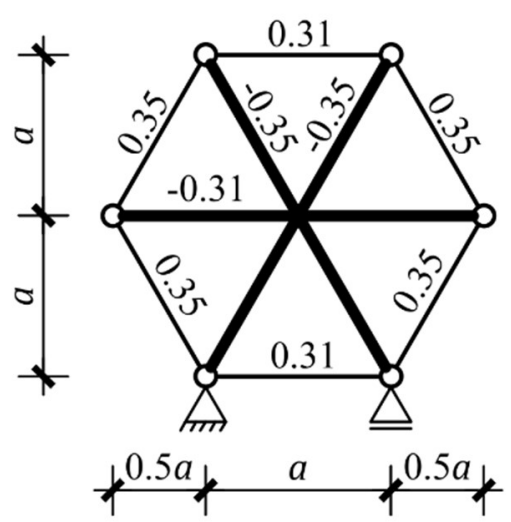

(b)
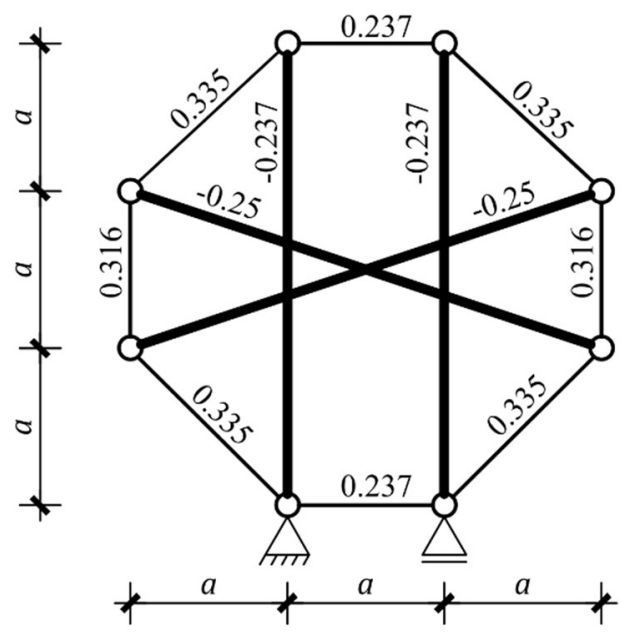

(d)

Figure 8. Values of self-stress state for four pure tensegrity trusses (a-d).

For all the trusses there is one zero eigenvalue in matrix $\mathbf{M}$ which is responsible for the existence of the one self-stress state $(S)$ shown in Figure 8. For these trusses the system of compression members (thick red line) is discontinuous $(D)$ and included inside the set of components in tension $(I)$, which are cables $(C)$.

For the first two cases (Figure $8 \mathrm{a}, \mathrm{b}$ ) there is one zero eigenvalue in matrix $\mathbf{L}$ responsible for the existence of one mechanism $(M)$. For the last two cases (Figure 8c,d) two mechanisms are identified. All mechanisms (Figure 9) are infinitesimal because eigenvalues of $\left(\mathbf{K}_{L}+\mathbf{K}_{G}\right)$ are positive. The analyzed trusses are pure tensegrities with infinitesimal mechanisms stabilized by one self-stress.

According to the features presented above the tensegrities presented in Figure 8 are promising as unit cells for the applications of 2D metamaterials with unusual mechanical properties [30]. 

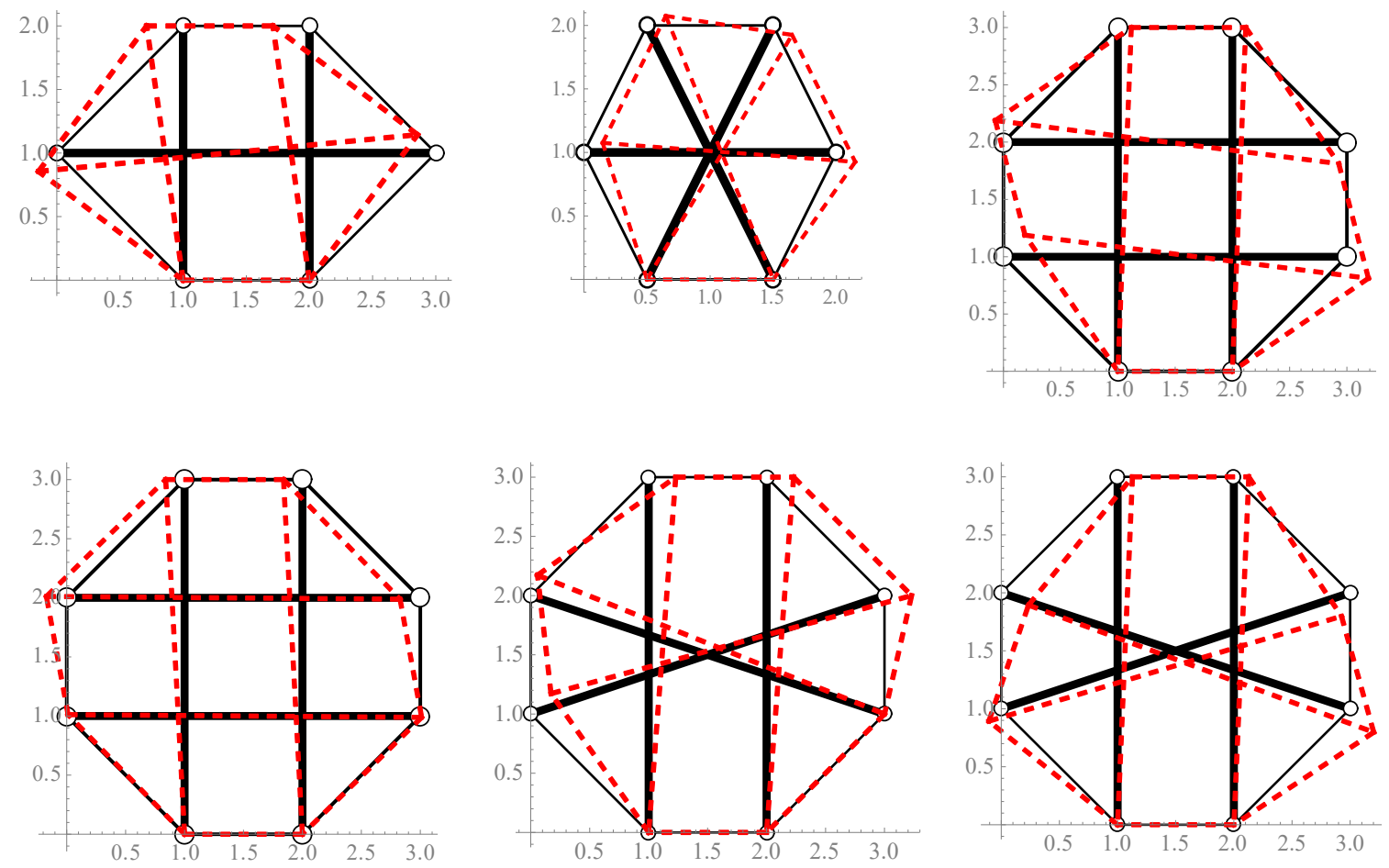

Figure 9. Mechanisms of pure tensegrity trusses.

An interesting, as well as instructive, example is presented in Figure 10a. It is the simplest truss $(T)$ with two elements $(n=2)$ and two d.o.f. $(m=2)[6,8,20,64,77] \mathbf{q}=\left[\begin{array}{ll}q_{3} & q_{4}\end{array}\right]^{T}$. Here, the compatibility matrix is square $\mathbf{B}\left(\in \mathbb{R}^{2 \times 2}\right)$, thus the matrices $\mathbf{L}$ and $\mathbf{M}\left(\in \mathbb{R}^{2 \times 2}\right)$ are the same:

$$
\mathbf{L}=\mathbf{M}=\operatorname{diag}\left[\begin{array}{ll}
2 & 0
\end{array}\right]
$$

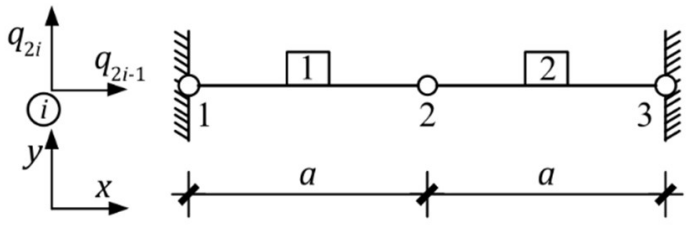

(a)

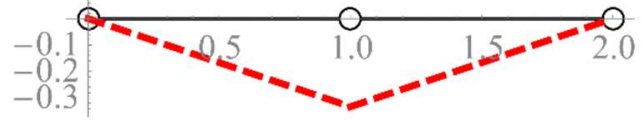

(b)

Figure 10. A truss with no tensegrity features: (a) geometry, (b) mechanism $\mathbf{x}_{2}$.

The zero eigenvalue in $\mathbf{L}$ and $\mathbf{M}$ is responsible for the existence of the mechanism $(M)$ (Figure 10b):

$$
\mathbf{x}_{2}=\left\{\begin{array}{ll}
0 & -1
\end{array}\right\}
$$

and the self-stress state $(S)$ :

$$
\mathbf{y}_{2}=\left\{\begin{array}{ll}
0.707 & 0.707
\end{array}\right\} \text {. }
$$

In this case, all eigenvalues of the matrix $\left(\mathbf{K}_{L}+\mathbf{K}_{G}\right)$ are positive:

$$
\mathbf{O}=\operatorname{diag}\left[\begin{array}{ll}
2.00 & 1.41
\end{array}\right]
$$

which indicates that the mechanism is balanced by the self-stress state. This structure does not satisfy the conditions of discontinuous compression members and the inclusion of compression elements 
within the set of elements in tension because there are no compression elements-the self-stress is balanced by reactions of the support. The truss is not a tensegrity because of lack of $C, D$, and $I$ features. On the other hand, this is a good and instructive example to show the intuitive infinitesimal mechanism stabilized by also intuitive self-stress.

The review of the literature revealed four qualitatively different examples wrongly classified into the class of tensegrities. This set of structures was an inspiration to the 3D tensegrities:

- $\quad$ the truss $(T)$ with 12 elements $(n=12)$ and nine d.o.f. $(m=9)$ [41] (Figure 11a),

- the truss $(T)$ with 16 elements $(n=16)$ and 13 d.o.f. $(m=13)[4,33,77,89,90]$ (Figure 11b),

- $\quad$ the truss (T) with 16 elements $(n=16)$ and 13 d.o.f. $(m=13)$ [33] (Figure 11c),

- the truss (T) with nine elements $(n=9)$ and nine d.o.f. $(m=9)$ [91] (Figure 11d).

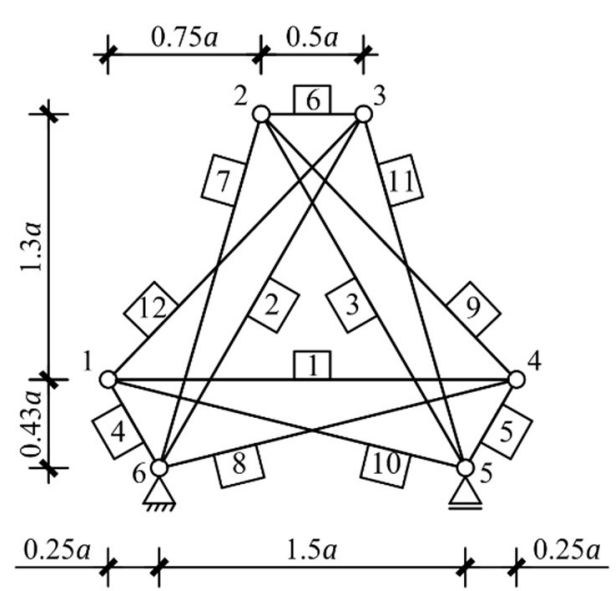

(a)

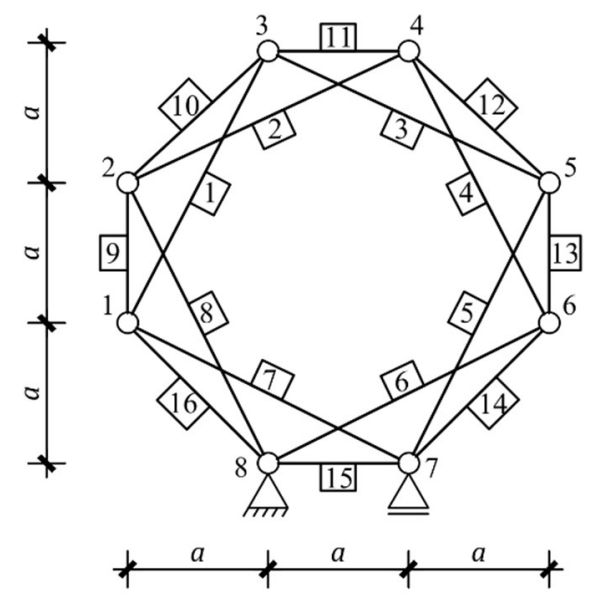

(c)

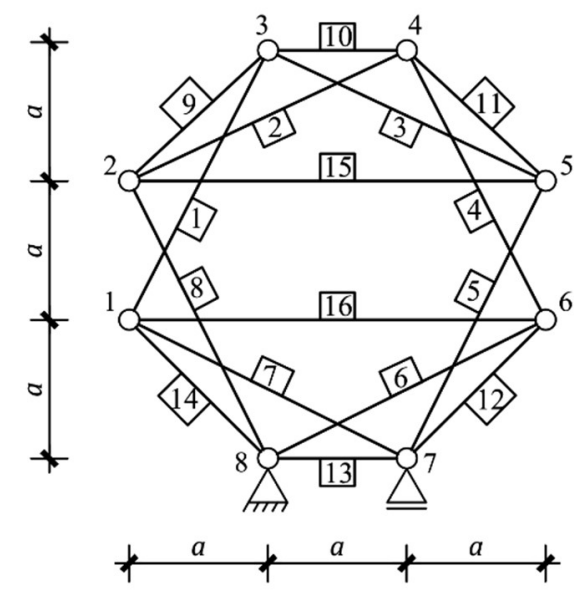

(b)

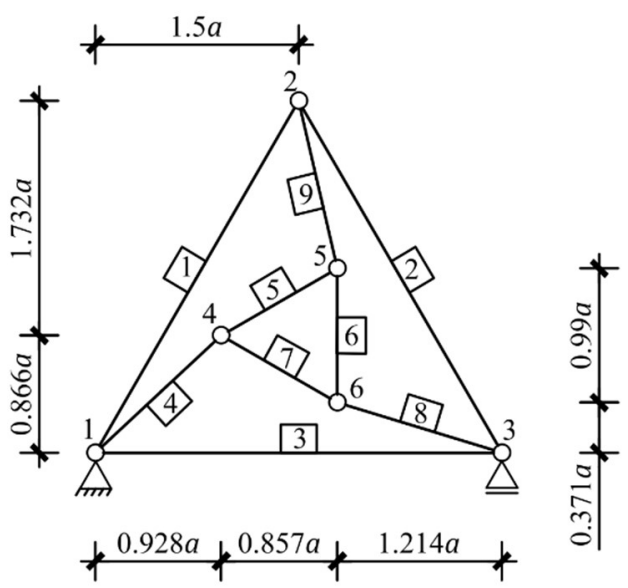

(d)

Figure 11. Four trusses (a-d) with no tensegrity features.

For the first three examples (Figure 11a-c), there is no zero eigenvalue in the matrix $\mathbf{L}$ which means that the system lacks the mechanism. There are three zero eigenvalues in the matrix $\mathbf{M}$, which are responsible for the existence of three different self-stress states (S). Two of them lead to the positive eigenvalues of the matrix $\left(\mathbf{K}_{L}+\mathbf{K}_{G}\right)$, and the third self-stress gives one negative eigenvalue. Several combinations of the three identified self-stress states are possible. It is impossible to clearly define which elements are compressed and which are tensioned. This truss is not a tensegrity because of the absence of both the mechanism and $D$ and $I$ features. 
For the last case (Figure 11d) the absence of zero eigenvalues in matrices $\mathbf{L}$ and $\mathbf{M}$ indicates the lack of mechanisms and self-stress states, respectively. This truss is not a tensegrity.

To the end, two interesting examples are shown:

- $\quad$ truss $(T)$ with five elements $(n=5)$ and four d.o.f. $(m=4)$ [36] (Figure 12a),

- $\quad$ truss $(T)$ with five elements $(n=5)$ and four d.o.f. $(m=5)$ (Figure $12 b)$.

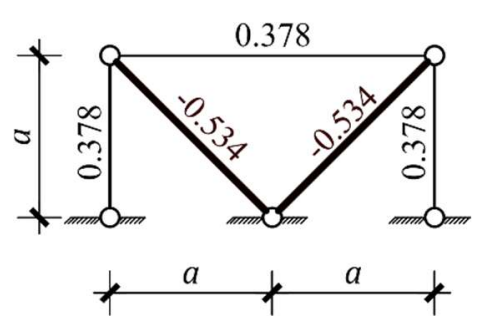

(a)

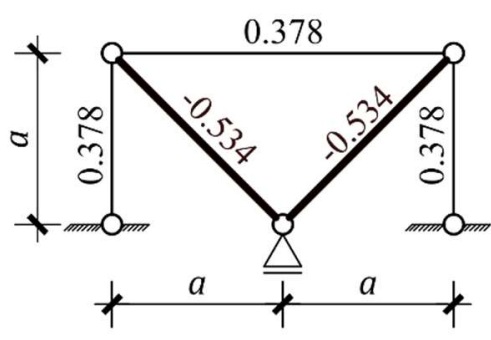

(b)

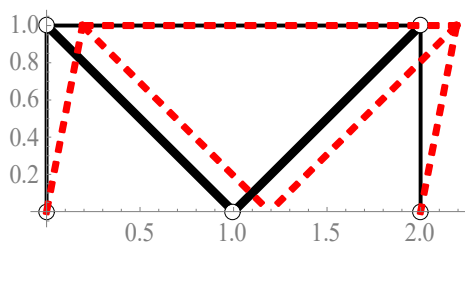

(c)

Figure 12. Truss with no tensegrity features: (a) values of self-stress state, (c) mechanism for truss shown in (b).

For the first truss, there is no zero eigenvalue in the matrix $\mathbf{L}$ which means that the system lacks the mechanism. There is one zero eigenvalue in the matrix $\mathbf{M}$ which is responsible for the existence of the one self-stress state $(S)$, as shown in Figure 11a. This structure does not satisfy the condition of discontinuous compression members (thick red line) and the inclusion of compression components inside the set of tension components, which are cables $(C)$. In [36] this truss is called "a two-dimensional tensegrity structure", but because of the absence of both the mechanism and $D$ and $I$ features, the truss is not a tensegrity.

A change of support (Figure 12b) caused one zero eigenvalue in the matrix $\mathbf{L}$ responsible for the existence of one mechanism (Figure 12c). The self-stress state is the same as for previous truss (Figure $11 b$ ), but one eigenvalue of the matrix $\left(\mathbf{K}_{L}+\mathbf{K}_{G}\right)$ is negative. This means structural instability - the mechanism is not stabilized by the self-stress state. The truss is not a tensegrity.

The term "tensegrity" used for the above examples in the references $[4,33,36,41,77,89,90]$ is incorrect.

\section{Summary and Conclusions}

The qualitative evaluation of truss structures featured in this paper was used for tensegrity form finding. New, precise definition was proposed. Characteristic features of tensegrity structures were used to classify the structures described in the literature as "pure tensegrities" or "structures with tensegrity features". Only in the case of pure tensegrities (structures with all six characteristic features) is it possible to control truss properties, such as stiffness and natural frequency, by changing the level of self-stress.

The existing form-finding methods determine the self-equilibrated configuration in the absence of externally applied loads, but they are not always define other characteristic features of tensegrity structures. The identification of the self-stress state in a truss is not sufficient to call it a tensegrity structure. From the point of view of structural mechanics, one of the most important tensegrity features is the mechanism - the uniqueness of tensegrity structures is based on the fact that self-stress states stabilize existing infinitesimal mechanisms. The absence of the mechanism brings the trusses into the group of structures with tensegrity features.

In this paper, singular value decomposition of the compatibility matrix was used to determine the states of self-stress and mechanisms. The nonlinear analysis with the use of geometric stiffness matrix, which takes into account the impact of the self-stress state was used to establish whether 
the mechanism was infinitesimal or finite. The other characteristic features of tensegrity structures, that satisfy the condition of discontinuous compression members and the inclusion of compression components inside the set of tension components (cables) were determined indirectly by the identified self-stress state.

The compatibility matrix and the stiffness matrix with the effect of self-equilibrated forces were determined using the finite element method. The geometrical and material characteristics were not taken into account because the characteristic features of tensegrity structures do not depend on them.

The proposed method of evaluation allowed a precise understanding of this unusual structure and a way to specify the correct use of this term in these applications. The results are summarized in Table 1. Some 2D pure tensegrity structures (according to the proposed definition) exist, but most of the trusses are incorrectly named in the literature. The term "tensegrity" is misused and overused in the literature. Three pure tensegrities can be distinguished, with one infinitesimal mechanism stabilized by one self-stress. Three other more complex structures are pure tensegrities with two infinitesimal mechanisms stabilized by one self-stress.

Table 1. Summary of the results.

\begin{tabular}{|c|c|c|c|c|c|c|c|}
\hline \multirow{2}{*}{ Example } & $T$ & $S$ & $C$ & $M$ & $D$ & $I$ & \multirow{2}{*}{ Classification of the Structure } \\
\hline & \multicolumn{3}{|c|}{ Obligatory Features } & \multicolumn{3}{|c|}{ Min. One of $\{M, D, I\}$} & \\
\hline Figure $2 \mathrm{a}$ & + & 1 & + & - & + & + & tensegrity features \\
\hline Figure $2 b$ & + & 1 & + & - & + & + & tensegrity features \\
\hline Figure $4 a$ & + & 1 & + & - & + & + & tensegrity features \\
\hline Figure $4 b$ & + & 1 & + & - & + & + & tensegrity features \\
\hline Figure $4 c$ & + & 1 & + & - & + & + & tensegrity features \\
\hline Figure $4 \mathrm{~d}$ & + & 3 & + & - & + & + & tensegrity features \\
\hline Figure $5 a$ & + & 1 & + & 1 & + & + & pure tensegrity \\
\hline Figure 6 & + & 1 & + & 2 & + & + & pure tensegrity \\
\hline Figure $8 \mathrm{a}$ & + & 1 & + & 1 & + & + & pure tensegrity \\
\hline Figure $8 b$ & + & 1 & + & 1 & + & + & pure tensegrity \\
\hline Figure $8 c$ & + & 1 & + & 2 & + & + & pure tensegrity \\
\hline Figure $8 d$ & + & 1 & + & 2 & + & + & pure tensegrity \\
\hline Figure 10a & + & 1 & - & 1 & - & - & non tensegrity \\
\hline Figure 11a & + & 3 & - & - & - & - & non tensegrity \\
\hline Figure $11 b$ & + & 3 & - & - & - & - & non tensegrity \\
\hline Figure 11c & + & 3 & - & - & - & - & non tensegrity \\
\hline Figure $11 d$ & + & - & - & - & - & - & non tensegrity \\
\hline Figure $12 \mathrm{a}$ & + & 1 & - & - & - & - & non tensegrity \\
\hline Figure $12 b$ & + & 1 & - & - & - & - & non tensegrity \\
\hline
\end{tabular}

In conclusion, tensegrity is overused in the literature on the subject, in particular, in the field of 2D models, where intuitive understanding of the specific features should be the easiest. Examples of pure tensegrities shown in Figures 5a and 6, and their extensions, can be recommended as 2D computational models for use in the coverings for stadiums and halls. The schemes from Figure 8 can be the basis for the construction of 2D metamaterials with specific mechanical features. The unit cells presented in Figures $5 \mathrm{a}$ and 8 are recommended as metamaterial unit cells. It should be noted that tensegrity trusses with computational schemes presented in Figures $5 a, 6$ and 8 can be successfully applied as deployable or smart engineering structures with monitoring, self-control, self-repair, and active control.

Author Contributions: Introduction was prepared by P.O. and W.G. Definition of tensegrity and mathematical description were written by P.O., J.K. and W.G. Results were obtained by P.O. and J.K. The analysis of the results and conclusions were written by P.O. and W.G.

Funding: This research received no external funding. 
Conflicts of Interest: The authors declare no conflict of interest.

\section{References}

1. Fuller, R.B. Tensile-Integrity Structures. U.S. Patent 3,063,521, 13 November 1962.

2. Snelson, K. Continuous Tension, Discontinuous Compression Structures. U.S. Patent 3,169,611, 16 February 1965.

3. Emmerich, D.G. Construction de Reseaux Autotendants. French Patent 1,377,290, 28 September 1964.

4. Pugh, A. An Introduction to Tensegrity; University of California Press: Berkeley, CA, USA, 1976.

5. Motro, R. Tensegrity systems: The state of the art. Int. J. Space Struct. 1992, 7, 75-83. [CrossRef]

6. Motro, R. Tensegrity. Structural Systems for the Future; Kogan Page: London, UK, 2003.

7. Hanaor, A. Geometrically rigid double-layer tensegrity grids. Int. J. Space Struct. 1994, 9, 227-238.

8. Tibert, G. Deployable Tensegrity Structures for Space Applications. Ph.D. Thesis, Royal Institute of Technology, Stockholm, Sweden, 2002.

9. Tibert, A.G.; Pellegrino, S. Deployable Tensegrity Masts. In Proceedings of the 44th AIAA/ASME/ASCE/ AHS/ASC Structures, Structural Dynamics and Materials Conference and Exhibit, Norfolk, VA, USA, 7-10 April 2003.

10. Wang, B.B. Cable-strut systems: Part I-Tensegrity. J. Constr. Steel Res. 1998, 45, 281-289. [CrossRef]

11. Zhang, J.Y.; Ohsaki, M. Tensegrity Structures. Form, Stability, and Symmetry; Springer: Tokyo, Japan, 2015; ISBN 978-4-431-54812-6.

12. Skelton, R.E.; de Oliveira, M.C. Tensegrity Systems; Springer: London, UK, 2009.

13. Skelton, R.E.; Helton, J.W.; Adhikari, R.; Pinaud, J.P.; Chan, W. An introduction to the mechanics of tensegrity structures. In Handbook of Mechanical Systems Design (Chapter 17); CRC Press: Boca Raton, FL, USA, 2002.

14. Skelton, R.E.; Adhikari, R.; Pinaud, J.P.; Chan, W.; Helton, J.W. An Introduction to the Mechanics of Tensegrity Structures. In Proceedings of the 40th IEEE Conference on Decision and Control, Orlando, FL USA, 4-7 December 2001; pp. 4254-4258.

15. Skelton, R.E.; Pinaud, J.P.; Mingori, D.L. Dynamics of the shell class of tensegrity structures. J. Franklin Inst. 2001, 338, 255-320. [CrossRef]

16. Masic, M.; Skelton, R.E. Deployable Plates Made from Stable-element Class 1 Tensegrity. In Proceedings of the Smart Structures and Materials 2002: Industrial and Commercial Applications of Smart Structures Technologies, San Diego, CA, USA, 17-21 March 2002; pp. 220-230.

17. Skelton, R.E.; Williamson, D.; Han, J.H. Equilibrium conditions of a class 1 tensegrity structures. Adv. Astronaut. Sci. Spacefl. Mech. 2002, 112, 927-950.

18. Williamson, D.; Skelton, R.E.; Han, J.H. Equilibrium conditions of class 1 tensegrity structures. Revue Francaise de Genie Civil 2003, 7, 291-310. [CrossRef]

19. Gilewski, W.; Kłosowska, J.; Obara, P. Applications of tensegrity structures in civil engineering. Procedia Eng. 2015, 111, 242-248. [CrossRef]

20. Kasprzak, A. Evaluation of Possibilities of Applications of Tensegrity Structures in Bridge Engineering. Ph.D. Thesis, Warsaw University of Technology, Warsaw, Poland, 2014.

21. Kawaguchi, M.; Tatemichi, I.; Chen, P.S. Optimum shapes of a cable dome structure. Eng. Struct. 1999, 21, 719-725. [CrossRef]

22. Masic, M.; Skelton, R.E. Optimization of Class 2 Tensegrity Towers. In Proceedings of the SPIE's 11th Annual International Symposium on Smart Structures and Materials, San Diego, CA, USA, 14-18 March 2004.

23. Tibert, A.G.; Pellegrino, S. Deployable tensegrity reflectors for small satellites. J. Spacecr. Rockets 2002, 39, 701-709. [CrossRef]

24. Gilewski, W.; Al Sabouni-Zawadzka, A. On possible applications of smart structures controlled by self-stress. Arch. Civ. Mech. Eng. 2015, 15, 469-478. [CrossRef]

25. Singh, G.; Ni, R.; Marwaha, A. A review of metamaterials and its applications. Int. J. Eng. Trends Technol. 2015, 19, 305-310. [CrossRef]

26. Wang, Y.T.; Liu, X.N.; Zhu, R.; Hu, G.K. Wave propagation in tunable lightweight tensegrity metastructure. Sci. Rep. 2018, 8, 11482. [CrossRef] [PubMed]

27. Fraddosio, A.; Marzano, S.; Pavone, G.; Piccioni, M.D. Morphology and self-stress design of V-Expander tensegrity cells. Compos. Part B 2017, 115, 102-116. [CrossRef] 
28. Fraternali, F.; Senatore, L.; Daraio, C. Solitary waves on tensegrity lattices. J. Mech. Phys. Solids 2012, 60, 1137-1144. [CrossRef]

29. Zhang, Q.; Zhang, D.; Dobah, Y.; Scarpa, F.; Fernando Fraternali, F.; Skelton, R. Tensegrity cell mechanical metamaterial with metal rubber. Appl. Phys. Lett. 2018, 113, 031906. [CrossRef]

30. Gilewski, W.; Al Sabouni-Zawadzka, A. Smart metamaterial based on the simplex tensegrity pattern. Materials 2018, 11, 673.

31. Murakami, H.; Nashimura, Y. Initial shape finding and modal analyses of cyclic right-cylindrical tensegrity modules. Comput. Struct. 2001, 79, 891-917. [CrossRef]

32. Masic, M.; Skelton, R.E.; Gill, P.E. Algebraic tensegrity form-finding. Int. J. Solids Struct. 2005, 42, 4833-4858. [CrossRef]

33. Paul, C.; Lipson, H.; Cuevas, F.V. Evolutionary Form-Finding of Tensegrity Structures. In Proceedings of the 2005 Conference: Genetic \& Evolutionary Computation, Washington, DC, USA, 25-29 June 2005.

34. Zhang, J.Y.; Ohsaki, M. Adaptive force density method for form-finding problem of tensegrity structures. Int. J. Solids Struct. 2006, 43, 5658-5673. [CrossRef]

35. Gomez Estrada, G.; Bungartz, H.J.; Mohrdieck, C. Numerical form-finding of tensegrity structures. Int. J. Solids Struct. 2006, 43, 6855-6868. [CrossRef]

36. Micheletti, A.; Williams, W.O. A marching procedure for form-finding for tensegrity structures. J. Mech. Mater. Struct. 2007, 2, 857-882. [CrossRef]

37. Tran, H.C.; Lee, J. Advanced form-finding of tensegrity structures. Comput. Struct. 2010, 88, $237-246$. [CrossRef]

38. Tran, H.C.; Lee, J. Form-finding of tensegrity structures using double singular value decomposition. Eng. Comput. 2011, 29, 71-86. [CrossRef]

39. Tran, H.C.; Lee, J. Form-finding of tensegrity structures with multiple states of self-stress. Acta Mech. 2011, 222, 131-147. [CrossRef]

40. Koohestani, K. Form-finding of tensegrity structures via genetic algorithm. Int. J. Solids Struct. 2011, 49, 739-747. [CrossRef]

41. Lee, S.J. A form-finding of planar tensegrity structures. Archit. Res. 2012, 14, 143-152. [CrossRef]

42. Tibert, A.G.; Pellegrino, S. Review of form-finding methods for tensegrity structures. Int. J. Space Struct. 2003, 18, 209-223. [CrossRef]

43. Juan, S.H.; Tur, J.M.M. Tensegrity frameworks. Static analysis review. Mech. Mach. Theory 2008, 43, 859-881. [CrossRef]

44. Veenendaal, D.; Block, P. An overview and comparison of structural form finding methods for general networks. Int. J. Solids Struct. 2012, 49, 3741-3753. [CrossRef]

45. Harichandran, A.; Yamini SreevalIndian, I. Form-finding of tensegrity structures based on force density method. J. Sci. Technol. 2016, 9. [CrossRef]

46. Zhanga, L.-Y.; Zhua, S.-X.; Lia, S.-X.; Xub, G.-K. Analytical form-finding of tensegrities using determinant of force-density matrix. Compos. Struct. 2018, 189, 87-98. [CrossRef]

47. Caia, J.; Wanga, X.; Dengb, X.; Fenga, J. Form-finding method for multi-mode tensegrity structures using extended force density method by grouping elements. Compos. Struct. 2018, 187, 1-9. [CrossRef]

48. Xua, X.; Wangb, Y.; Luoc, Y. Finding member connectivities and nodal positions of tensegrity structures based on force density method and mixed integer nonlinear programming. Eng. Struct. 2018, 166, 240-250. [CrossRef]

49. Bathe, K.J. Finite Element Procedures in Engineering Analysis; Prentice Hall: New York, NY, USA, 1996.

50. Zienkiewicz, O.C.; Taylor, R.L. The Finite Element Method. Vol. 1. The Basis; Elsevier Butterworth-Heinemann: London, UK, 2000.

51. Gilewski, W.; Kasprzak, A. Introduction to mechanics of tensegrity modules. In Theoretical Foundation of Civil Engineering. Mechanics of Structures and Materials; Jemioło, S., Lutomirski, S., Eds.; OWPW: Warsaw, Poland, 2012; Volume 1, pp. 83-94.

52. Calladine, C.R. Buckminster Fuller's “tensegrity" structures and clerk Maxwell's rules for the construction of stiff frames. Int. J. Solids Struct. 1978, 14, 161-172. [CrossRef]

53. Calladine, C.R. Modal stiffnesses of a pretensioned cable net. Int. J. Solids Struct. 1982, 18, 829-846. [CrossRef]

54. Pellegrino, S.; Calladine, C.R. Matrix analysis of statically and kinematically indeterminate frameworks. Int. J. Solids Struct. 1986, 22, 409-428. [CrossRef] 
55. Pellegrino, S. Analysis of prestressed mechanisms. Int. J. Solids Struct. 1990, 26, 1329-1350. [CrossRef]

56. Calladine, C.R.; Pellegrino, S. First order infinitesimal mechanisms. Int. J. Solids Struct. 1991, $27,505-515$. [CrossRef]

57. Golub, G.; Kahan, W. Calculating the singular values and pseudo-inverse of a matrix. J. SIAM Numer. Anal. Ser. B 1965, 2, 205-224. [CrossRef]

58. Klema, V.C. The singular value decomposition: It's computation and some applications. IEEE Trans. Automatic Control 1980, 25, 164-176. [CrossRef]

59. Leon, S.J. Linear Algebra with Applications; Macmillan: New York, NY, USA, 1994.

60. Long, C. Visualization of matrix singular value decomposition. Math. Mag. 1983, 56, 161-167. [CrossRef]

61. Mc Guire, W.; Gallagher, R.H. Matrix Structural Analysis; Wiley: New York, NY, USA, 1979.

62. Stewart, G.W. Matrix Algorithms: Basic Decompositions; SIAM: Philadelphia, PA, USA, 1998.

63. Strang, G. Introduction to Linear Algebra; Wellesley-Cambridge Press: Wellesley, MA, USA, 1993.

64. Gilewski, W.; Kłosowska, J.; Obara, P. Application of singular value decomposition for qualitative analysis of truss and tensegrity structures. ACTA Sci. Polon. Ser. Archit. 2015, 14, 3-20.

65. Pellegrino, S. Structural computations with the singular value decomposition of the equilibrium matrix. Int. J. Solids Struct. 1993, 30, 3025-3035. [CrossRef]

66. Rahami, H.; Kaveh, A.; Ardalan Asl, M.; Mirghaderi, S.R. Analysis of near-regular structures with node irregularity using SVD of equilibrium matrix. Int. J. Civ. Eng. 2013, 11, 226-239.

67. Motro, R. Structural morphology of tensegrity systems. Build. Hous. 2009, 10, 1-19.

68. Ashwear, N.; Eriksson, A. Natural frequencies describe the pre-stress in tensegrity structures. Comput. Struct. 2014, 138, 162-171. [CrossRef]

69. Ashwear, N.; Eriksson, A. Influence of temperature on the vibration properties of tensegrity structures. Int. J. Mech. Sci. 2015, 99, 237-250. [CrossRef]

70. Connelly, R.; Back, A. Mathematics and tensegrity. Am. Sci. 1998, 86, 142-151. [CrossRef]

71. Moored, K.W.; Bart-Smith, H. Investigation of clustered actuation in tensegrity structures. Int. J. Solids Struct. 2009, 46, 3272-3281. [CrossRef]

72. Moored, K.W.; Kemp, T.H.; Bart-Smith, H. Analytical prediction, optimization, and design of a tensegrity-based artificial pectoral fin. Int. J. Solids Struct. 2011, 48, 3142-3159. [CrossRef]

73. Skelton, R.E.; de Oliveira, M.C. Optimal complexity of deployable compressive structures. J. Franklin Inst. 2010, 347, 228-256. [CrossRef]

74. Tran, H.C.; Lee, J. Initial self-stress design of tensegrity grid structures. Comput. Struct. 2010, 88, 558-566. [CrossRef]

75. Tran, H.C.; Lee, J. Self-stress design of tensegrity gird structures with exostresses. Int. J. Solids Struct. 2010, 47, 2660-2671. [CrossRef]

76. Williamson, D.; Skelton, R.E.; Han, J. Equilibrium conditions of a tensegrity structure. Int. J. Solids Struct. 2003, 40, 6347-6367. [CrossRef]

77. Zhang, J. Structural Morphology and Stability of Tensegrity Structures. Ph.D. Thesis, Kyoto University, Kyoto, Japan, 2007.

78. Zhang, J.Y.; Ohsaki, M. Stability conditions for tensegrity structures. Int. J. Solids Struct. 2007, 44, 3875-3886. [CrossRef]

79. Chan, W.L.; Skelton, R.E. Equilibria and Stiffness of Planar Tensegrity Structures. In Proceedings of the AAS/AIAA Space Flight Mechanics Meeting, San Antonio, TX, USA, 27-30 January 2002.

80. Ohsaki, M.; Zhang, J. Stability conditions of prestressed pin-joint structures. Int. J. Nonline Mech. 2006, 41, 1109-1117. [CrossRef]

81. De Jager, B.; Skelton, R.E. Stiffness of planar tensegrity truss topologies. Int. J. Solids Struct. 2006, 43, 1308-1330. [CrossRef]

82. Masic, M.; Skelton, R.E. Selection of prestress for optimal dynamic/control performance of tensegrity structures. Int. J. Solids Struct. 2006, 43, 2110-2125. [CrossRef]

83. Masic, M.; Skelton, R.E.; de Oliveira, M.C. Integrated Structure and Control Design of Modular Tensegrities. In Proceedings of the 44th IEEE Conference on Decision and Control, and the European Control Conference, Seville, Spain, 12-15 December 2005.

84. Masic, M.; Skelton, R.E.; Gill, P.E. Optimization of tensegrity structures. Int. J. Solids Struct. 2006, 42, 4687-4703. [CrossRef] 
85. Zhang, J.Y.; Ohsaki, M.; Kanno, Y. A direct approach to design of geometry and forces of tensegrity systems. Int. J. Solids Struct. 2006, 43, 2260-2278. [CrossRef]

86. Micheletti, A. On generalized reciprocal diagrams for self-stressed frameworks. Int. J. Space Struct. 2008, 23, 153-166. [CrossRef]

87. Deifeld, T.E.C.; de Oliveria Pauletti, R.M. Numerical Simulation of the Assembling of Tensegrity Domes. In Proceedings of the XXVI Iberian Latin-American Congress on Computational Methods in Engineering-CILAMCE 2005, Guarapari, Espirito Santo, Brasil, 19-21 October 2005.

88. Tran, H.C.; Lee, J. Determination of a unique configuration of free-form tensegrity structures. Acta Mech. 2011, 220, 331-348. [CrossRef]

89. Micheletti, A.; Cadoni, D. Design of Single-Layer Floating-Compression Tensegrities. In Proceedings of the Colloque National en Calcul des Structures, CSMA 2011, Giens, France, 9-13 May 2011.

90. Zhang, J.Y.; Guest, S.D.; Connelly, R.; Ohsaki, M. Dihedral 'star' tensegrity structures. Int. J. Solids Struct. 2010, 47, 1-9. [CrossRef]

91. Connelly, R.; Fowler, P.W.; Guest, S.D.; Schulze, B.; Whiteley, W.J. When is a symmetric pin-jointed framework isostatic? Int. J. Solids Struct. 2009, 46, 762-773. [CrossRef]

(C) 2019 by the authors. Licensee MDPI, Basel, Switzerland. This article is an open access article distributed under the terms and conditions of the Creative Commons Attribution (CC BY) license (http://creativecommons.org/licenses/by/4.0/). 